\title{
A REVIEW OF TRAIT-MEDIATED INDIRECT INTERACTIONS IN ECOLOGICAL COMMUNITIES
}

\author{
EARl E. Werner ${ }^{1,3}$ AND Scott D. PeACOR ${ }^{2}$ \\ ${ }^{1}$ Department of Ecology and Evolutionary Biology, University of Michigan, Ann Arbor, Michigan 48109 USA \\ ${ }^{2}$ NOAA Great Lakes Environmental Research Laboratory, 2205 Commonwealth Blvd., Ann Arbor, Michigan 48105 USA \\ and Department of Fisheries and Wildlife, Michigan State University, East Lansing, Michigan 48824 USA
}

Abstract. In this paper we review the empirical studies documenting trait-mediated indirect interactions (TMIIs) in food webs. Basic models and empirical approaches that form the foundation of our conceptualization of species interactions generally assume that interactions are an intrinsic property of the two interacting species and therefore are governed by their respective densities. However, if a species reacts to the presence of a second species by altering its phenotype, then the trait changes in the reacting species can alter the per capita effect of the reacting species on other species and, consequently, population density or fitness of the other species. Such trait-mediated indirect interactions can reinforce or oppose density-mediated effects and have been largely overlooked by community ecologists. We first briefly develop the case for the broad mechanistic basis for TMIIs and then review the direct evidence for TMIIs in various permutations of simple three- to fourspecies food webs. We find strong evidence for quantitatively significant effects of TMIIs in a variety of aquatic and terrestrial systems. We further highlight those few studies that address the question of the relative magnitudes of density- and trait-mediated effects and the role of species densities in their transmission. These studies indicate that trait effects are often as strong or stronger than density effects. We conclude that ecological communities are replete with TMIIs arising from trait plasticity and that these effects are quantitatively important to community dynamics. Finally, we synthesize our results and indicate profitable directions for future research.

Key words: community structure; density-mediated indirect interactions; food webs; interaction modifications; phenotypic plasticity; trade-offs; trait-mediated indirect interactions.

\section{Introduction and the Conceptual Problem}

Ecological communities are among the most complex systems that natural scientists attempt to understand, and ecologists continue to search for a conceptualization of communities that will enable this understanding. For example, we would like to know the rules by which species are included or excluded from communities. How will relative abundances change as species are added or deleted, or as their environment is disturbed? What are the roles of history, spatial and temporal heterogeneity, and biodiversity? These questions are not only fundamental to a basic science of community ecology, but also are clearly central to the sciences of resource management and conservation biology.

In order to understand the causal basis for such properties of communities (or of any system), investigators typically abstract the system into component parts, develop an understanding of the relationships between the component parts, and then reassemble (conceptually or mathematically) the system to predict the con-

Manuscript received 25 September 2001; revised 3 February 2002; accepted 25 February 2002. Corresponding Editor: F. R. Adler. For reprints of this Special Feature, see footnote 1, p. 1081.

${ }^{3}$ E-mail: eewerner@umich.edu sequences of various changes in, or perturbations to, the system. To be successful at this enterprise, we must abstract the component parts of the system such that they are reasonably unchanging when assembled into different configurations. If component parts change when a new configuration of the system is assembled, then our ability to understand and predict system dynamics is obviously limited. This is a problem that biology confronts at all levels; e.g., do genes have the same effect on different backgrounds, or is a developmental sequence altered by the proximity of different tissues (e.g., Lewontin 2000). Directly relevant to the question at hand, are the consequences of species interactions consistent when these species are embedded in different communities or placed in different environments?

Basic models that form the foundation of our conceptualization of these interactions, such as the LotkaVolterra equations and derivatives, generally assume that interactions are an intrinsic property of the two interacting species and therefore are governed by their respective densities. That is, parameters determining the strength of interactions between species (the interaction coefficients) effectively are assumed to be independent of the community milieu in which these species are embedded. Consequently, more complex communities can be assembled from these pairwise inter- 
action "building blocks." In a food web context, for example, the consumer-resource interaction is the basic direct interaction link between two species, and these species then interact indirectly with others through chains of such direct interactions. These indirect effects are therefore propagated by changes in densities of intervening species, or density-mediated indirect interactions (hereafter DMIIs; Abrams 1995). Keystone predator effects, trophic cascades, and exploitative competition are all indirect effects traditionally conceived as being transmitted through changes in densities of intervening species in food webs (e.g., Paine 1966, Oksanen et al. 1981).

If we abstract species as the basic component of the community, then it is the unique sets of traits these species possess that determine the "intrinsic" interaction strength. For example, the act of a predator capturing prey depends on a host of such traits: e.g., size, speed, trophic apparatus, searching ability, and pursuit strategy of the predator, as well as the size, speed, activity, morphology, and crypticity of the prey. Species traits clearly change through selection imposed by interactions with other species, but such adjustments present little problem for the traditional "pairwise building block" approach of community ecology. We simply assume that such trait changes occur slowly relative to the population dynamics that are responsible for the community patterns we are interested in. We then can determine the relationship between (fixed) species traits and interaction strengths that can be employed in theoretical frameworks to predict community dynamics (e.g., Laska and Wootton 1998, Berlow et al. 1999, Abrams 2001).

A fundamental problem arises, however, when species modify their phenotype in response to the presence of other species. If a species reacts to the presence of a second species by altering its phenotype, the trait changes in the reacting species can alter the per capita effect of the reacting species on other species (a form of higher order interaction; e.g., Vandermeer 1969), even in the absence of density effects of the second on the reacting species. As a consequence, trait plasticity causes another form of indirect effect to be transmitted through the food web, i.e., a trait-mediated indirect interaction (hereafter TMII; Abrams 1995), also termed behavioral indirect interactions (Abrams 1984, Miller and Kerfoot 1987) and interaction modifications (Wootton 1993). There are a host of well-known modalities for such phenotypic responses; these responses may be developmental, morphological, physiological, life historical, and behavioral (Stearns 1989, Schlichting and Pigliucci 1998, Tollrian and Harvell 1999). Clearly, these are all traits that can influence species interactions.

For example, most predator-prey studies focus solely on the rate at which the predator consumes prey and the consequent effects on the prey density, rather than any influence of the predator on the phenotype of the surviving prey. However, if a species reacts behaviorally to a predator by reducing activity or increasing refuge use, this can alter its impact on resources in the same way that density changes do. Consequently, these alterations in traits of the surviving prey can cause trophic cascades or can affect competitive relationships with other species independent of effects on prey removal. It is this change in per capita effects that is the critical issue conceptually. Examination of TMIIs is simply a convenient framework for demonstrating the effects of trait plasticity on changes in per capita interaction strengths. As previously noted, this "context dependence" of interactions is a problem at all levels in biology (e.g., Lewontin 2000), and the challenge is to devise methods to conceptualize and analyze system properties when individual components are essentially adaptive modules, or at least predictable in the way that they change with system configuration.

We argue that ecological communities are replete with trait-mediated indirect effects that arise from phenotypic plasticity and that these effects are quantitatively important to community dynamics. We further suggest that confronting the mechanisms of species interactions highlights the ubiquity and potential impacts of TMIIs in ecological communities. Our approach will be to synthesize the lessons from the scattered empirical literature on TMIIs rather than to attempt an exhaustive review. Because the literature on TMIIs is not yet large, represents many different classes of effects, and rarely reports effect size when both trait and density effects occur, data are not sufficient to attempt a quantitative analysis of effect size, but we indicate the magnitudes of responses where we can. We first briefly develop the case for the broad mechanistic basis for TMIIs and then review the direct evidence for TMIIs in various permutations of simple food webs. We find strong evidence for quantitatively significant effects of TMIIs in a variety of aquatic and terrestrial systems. Further, we highlight the few studies that address the question of the relative magnitudes of density- and trait-mediated effects and the role of species densities in their transmission. Finally, we conclude by synthesizing our results and indicating profitable directions for future research.

\section{Ubiquity of the Requisite Mechanism: INDIVIDUAL-LEVEL TRAIT PLASTICITY}

The requisite mechanism for TMIIs, phenotypic plasticity in traits affecting species interactions, is universally represented in different taxa and communities. Phenotypic plasticity is ultimately related to the pervasive challenges that spatial and temporal heterogeneity of the environment present to an organism. A given phenotype rarely maximizes performance in all of the environments and communities experienced by a species, and thus traits simultaneously may be under selection pressures to increase or decrease their value depending on local circumstances. Phenotypic plastic- 
ity is one solution to this dilemma. In animals, the universality of this plasticity is reflected in the existence of the fields of behavior and behavioral ecology. Extensive phenotypic plasticity also has been documented in morphology, physiology, and life history in a wide variety of taxa, both plant and animal (Schlichting and Pigliucci 1998, Tollrian and Harvell 1999). Many of these phenotypic changes are responses to the presence of other species in the environment. For example, morphological responses to predators have been documented in protists, rotifers, cladocerans and various other crustaceans, bryozoans, gastropods, fish, and amphibians (Harvell 1990, Bronmark and Miner 1992, McCollum and VanBuskirk 1996, Relyea and Werner 2000). Morphological responses to competitors or to resources influenced by competitors have been documented in clonal marine invertebrates (Harvell 1990), amphibians (Relyea 2000), and fish (Wainwright et al. 1991, Wimberger 1991). We are only beginning to appreciate the ubiquity of nonbehavioral forms of phenotypic plasticity in animals, although these have long been documented in plants.

Moreover, because trait values hinge on allocation decisions, and allocation to one trait often comes at the cost of another, trade-offs exist. Quantitative expression of a trait may enhance one aspect of performance while decreasing another. The presence of such underlying trade-offs is one of the fundamental organizing features of ecological interactions (Levins 1968, MacArthur 1972, Tilman 1990, Werner 1998) and de facto will lead to TMIIs. For example, consider the fundamental consumer-resource linkage in the food web. Because most organisms are simultaneously consumers of, and resources for, other species, there is a series of trade-offs around traits associated with these linkages. Traits bestowing effectiveness at resource acquisition often are not consonant with avoiding predation from a higher trophic level. Perhaps the most prominently documented responses to these trade-offs are in behavioral traits. For example, the ability to obtain resources is often tightly associated with activity level, but activity also has a large impact on vulnerability to predators (e.g., Werner and Anholt 1993, Lima 1998a). Consequently, any alteration in activity due to presence of a predator comes at a cost in terms of interactions with competitors and vice versa. Lima (1998a) reviews 70 recent studies, conducted over less than a decade, demonstrating activity responses (decrease in activity and/or increased refuging) of a wide range of taxa on exposure to predators. Similarly, the evidence for the influence of both predators and competitors on the use of space (e.g., habitat shifts) by species is equally persuasive (Lima [1998a] reviews over 90 studies demonstrating such responses).

These few examples highlight the evidence that traits important to ecological interactions can be quite plastic and depend on ecological context. Further, this plasticity is often adaptive and therefore predictable to

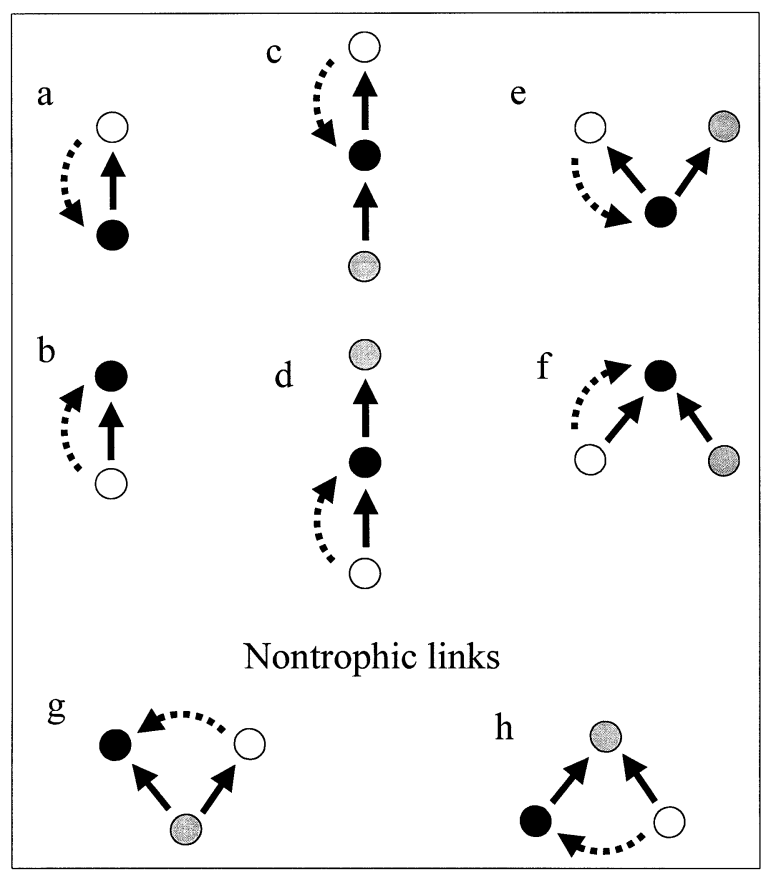

FIG. 1. Basic mechanisms of trait-mediated indirect effects. Species/agents causing a phenotypic response are represented by open circles; the species responding are represented by solid circles. Solid lines point in the direction of energy transfer; curved dashed lines indicate an effect on a trait of the species to which the arrow points. The figure illustrates: $(\mathrm{a}, \mathrm{b})$ fundamental trait effects (consumer on a resource and resource on a consumer); (c-f) the four unique patterns of trait transmission to a third species or the recipient of the TMII (gray circles); and ( $g, h$ ) examples of "nontrophic" (interference) effects added to webs (e) and (f).

some extent. Because these traits can largely define the magnitude of the interaction coefficients between species, we could expect that trait plasticity would cause significant TMIIs. The only rationale for ecologists to ignore the effects of trait dynamics, then, is that their effects are quantitatively small relative to density effects.

\section{The Consequences of Trait Plasticity to COMMUnity Dynamics}

In this section we examine empirical studies in which indirect effects due to trait changes in an intervening species have been documented. For each TMII type, we present representative studies and, if the study permitted, estimates of the magnitude of the trait-mediated effect. At the end of each section, we also indicate studies that suggest TMIIs were important, but where they were not explicitly examined.

We organize the presentation by the mechanism of transfer of trait effect (Fig. 1). Two fundamental mechanisms exist in the context of the basic consumer-resource link of food webs: (1) a predator/consumer can alter traits of its resource, and (2) a resource can alter traits of its consumer (Fig. 1a, b). In order for an in-

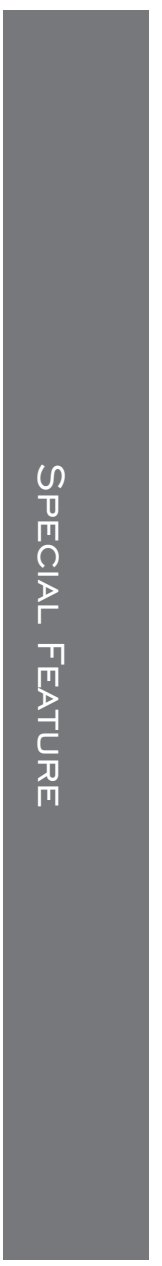


direct effect to occur, there must be a third species in the web and the trait effect must be transmitted indirectly to this third species. Transmission of the trait effect thus indicates that one species has altered the per capita effects of the reacting species on the third. For both of these two mechanisms, the trait effect subsequently can be transmitted through the reacting species to either: (1) a resource of the reacting species, or (2) a predator/consumer that feeds on the reacting species. This taxonomy leads then to four possible food web configurations giving different TMII transmission effects (Fig. 1c-f). Many of the TMIIs in more complex webs can be decomposed into one of these basic threespecies/two-link configurations. These configurations allow us to examine a very wide array of ecological interactions and the TMIIs that can be embedded in them. We also review other possibilities that build on these basic components by adding more links (e.g., interference competition as in Fig. $1 \mathrm{~g}$, $\mathrm{h}$, and the interaction of predation and exploitative competition). In more complex webs, the possibilities will exist for multiple trait links (the above are trait followed by density effects) or alternating trait and density effects in different combinations that may introduce additional phenomena (e.g., Abrams 1992).

\section{The three-species food chain}

We begin with studies where we can isolate a simple three-species (or trophospecies) linear food chain in which the middle species (consumer) adaptively responds to the density of the top predator and/or the resource (Fig. 1c,d). Thus the middle (reacting) species transmits effects of either or both of the two fundamental mechanisms outlined in Fig. 1a, b, and the resulting TMIIs can constitute either top-down or bottom-up effects.

Many excellent studies isolate a top-down trophic cascade to resources due to behavioral responses in activity (but often associated with spatial responses as well) of the intermediate consumer to a predator (Fig. 1c). Wissinger and McGrady (1993) quantified interactions between two dragonfly larvae: a top predator Tramea that can feed on Erythemis, which in turn feeds on damselflies. By conducting experiments in the nonlethal presence of Tramea (removing distal lobes of the labial menta so that they could not feed), they demonstrated that $61 \%$ fewer damselflies were consumed by Erythemis in the presence of Tramea. Intact Tramea reduced the density of Erythemis by $25 \%$ (presumably, then, the positive DMII on damselflies would be of this magnitude). Thus the authors argued that the trait effect was more than double the density effect under the conditions of these experiments. Huang and Sih (1991) demonstrated similar effects in a green sunfish, salamander, and isopod system. In the absence of fish, salamanders had strong effects on isopod survivorship, but in the presence of fish, salamanders had no effect on isopod survivorship. The effect on isopods through fish predation on the salamanders (a DMII) was small relative to the behavioral effect (a TMII) of reducing the foraging activity of salamanders (the trait effect was estimated to be 2.4 times the density effect). This result was also demonstrated in separate experiments quantifying salamander predation rates on isopods in the presence and absence of chemical cues of fish presence. The authors further argued that the trait-mediated (positive) effect of fish on isopods was comparable in magnitude to the direct (negative) effect of fish feeding on isopods.

We have conducted a number of experiments that indicate a strong top-down cascade from caged (nonlethal) odonate predators, through anuran larvae, to resources. In these studies, the anuran larvae responded to the presence of chemical cues of predator presence by reducing activity and altering space use (Werner 1991, Peacor and Werner 1997, Relyea 2001). The cascade to resources was indicated, in most cases, by the very substantial increase in the growth of competing species or size classes that did not respond to the predator (Werner 1991, Werner and Anholt 1996, Peacor and Werner 1997, 2000, 2001). Nystrom and Abjornsson (2000) also show a TMII due to the presence of fish cues on periphyton abundance through anuran larvae.

There are many reported examples of TMIIs for which the primary response of the intermediate species to the presence of predators appears to be habitat shifts. Turner and Mittelbach (1990) demonstrated that piscivorous bass cause bluegill to shift to littoral vegetation in ponds, with a consequent release of zooplankton populations in the center of the pond. Diaphanasoma was at least twice as abundant and Ceriodaphnia was 5-7.5 times as abundant in the presence of bass than in their absence. Bass caused no significant mortality of the bluegill, and thus the effect was strictly behaviorally mediated. Similarly, Soluk and Collins (1988) demonstrated that stoneflies only killed about one-third of the mayflies in the presence of fish (sculpin) as they did in their absence. Experiments employing sculpin with their mouths sewn shut indicated that most of the effect was due to behavioral responses of stoneflies to the presence of fish.

A series of different studies on the impact of mayflies on benthic algae demonstrates the effects of TMIIs. Mayflies, dominant grazers in many streams, often retreat under rocks or into interstitial spaces in the presence of fish, a behavior that reduces their grazing activity. For example, McIntosh and Townsend (1996) demonstrated in both laboratory and field experiments that fish have a strong cascading effect on algal resources in streams by modifying the behavior of mayflies. Algal biomass was more than two times greater on the tops of rocks in the presence of fish. Because there were no significant effects on mayfly density, all top-down effects on algae could essentially be attributed to the behavioral responses of the mayflies. Peck- 
arsky and McIntosh (1998) also showed that total algal biovolume was $30-35 \%$ higher in an artificial stream system when cues of trout and stonefly predators were presented to a mayfly. In a field experiment, Diehl et al. (2000) demonstrated a strong cascading effect of trout density on benthic algae, again primarily through effects on mayfly behavior (see also Kuhara et al. 1999, Gelwick 2000).

Turner $(1996,1997)$ showed that snails found in association with molluscivorous fish respond to chemical cues released by crushed conspecifics and move to safer (covered) habitats. Adding doses of crushed conspecifics to experimental pools had a negative effect on growth of the snails and on their use of open habitat, and a positive effect on periphyton abundance in the open habitat. At the end of the experiment, periphyton in open habitats with predator cues was 1.24-1.6 times higher than in controls without predator cues. Turner et al. (2000) further examined the responses of snails to two predators, fish and crayfish. Fish caused the snails to spend more time under cover and crayfish caused them to spend more time at the surface or on the upper sides of surfaces. Tank experiments indicated that the presence of caged fish caused periphyton abundances in covered habitats to be reduced to $8 \%$ of those in the absence of fish, while near-surface periphyton increased 1.6-fold. In contrast, the presence of caged crayfish had little effect on periphyton levels in covered habitats, but reduced periphyton in surface habitats to $39 \%$ of that in the absence of crayfish. Combined effects of the two predators led to intermediate levels of periphyton in both habitats, corresponding to the intermediate habitat use of the snails. This study is one of the few experiments to examine and contrast the effects of multiple predators and their combined effects on a trophic cascade.

Herbivores feeding on plants (or predators of these herbivores) also alter space use through their interactions with ants that can cause strong cascading TMIIs. Messina (1981) demonstrated that ants tending membracids (treehoppers) on goldenrod plants had large effects on goldenrod growth and reproduction via harassment of defoliating chrysomelid beetles. Ants attacked adult beetles, causing them to drop off the plants; larval chrysomelids crawled away when harassed by ants (Messina 1981). Stems with ants grew twice as much in height as those without ants and produced seven times as many seeds. In one season, essentially only those stems with ants produced any seeds at all. J. Scanio (personal communication) similarly isolated the direct consumptive and trait effects of ants on tent caterpillars feeding on wild cherry trees (ants use extrafloral nectaries of the wild cherry). Harassed caterpillars cease foraging and retreated to the web nest. When caterpillars were large, this behavioral effect resulted in nearly a $40 \%$ reduction in defoliation of the wild cherry trees. By excluding ants, duplicating mortality due to ants by removal (no cue of ants), and mimicking the harassment, Scanio was able to show that the TMII accounted for $\sim 60 \%$ of the total effect of ants on the reduction in defoliation rates on the wild cherries for large caterpillars and $22 \%$ for small caterpillars (see Fritz [1983], Gastreich [1999], and Haemig [1999] for other TMIIs involving ants; see Stamp and Bowers [1993] for TMIIs involving caterpillars).

Studies involving spatial responses make clear that that TMIIs from predators through consumers can lead to negative as well as positive effects on resources. Schmitz and colleagues have shown such effects in an old-field system due to behavioral responses (both activity and spatial) of grasshoppers to spiders. Schmitz (1998a) experimentally constructed a series of different food web configurations composed of grasses, forbs, generalist and specialist (on grasses) grasshopper species, and a spider predator. Spiders were either free to prey on the grasshoppers or had their chelicerae glued with nontoxic surgical cement to isolate the trait effect. Grasshoppers responded to spiders by reducing activity (see Beckerman et al. 1997) and shifting their diet to a greater proportion of herbs (see Rothley et al. 1997). Schmitz (1998a) found that grass biomass was 1.551.66 times greater with the generalist grasshopper when spiders were present and there was a net negative effect on herbs (see also Beckerman et al. 1997 where damage to grass was only $25 \%$ that without spiders, Schmitz et al. 1997). There were virtually no effects of spiders on grasshopper densities in any of the interaction webs that Schmitz constructed, and thus the changes in plant biomass in response to predator manipulations resulted from TMIIs (see also Pusenius and Ostfeld [2000] for experiments with stoats, voles and tree seedlings).

A number of other studies, both terrestrial and aquatic, do not partition trait from density effects of top predators, but suggest that top-down cascades to resources are strongly affected by behavioral responses to these predators (e.g., Power et al. 1985, Carpenter et al. 1987, Persson et al. 1993, Moran et al. 1996, Forrester et al. 1999). These and the studies previously cited suggest that TMIIs may be an important component of many of the trophic cascades that typically have been conceptualized as due to the density effects of top predators.

Now consider TMIIs arising "bottom-up" due to an intermediate consumer in a three-species food chain responding to resources (Fig. 1d). In most of the previous examples, consumers faced feeding/risk tradeoffs mediated either by activity levels or space use. Behavioral ecological theory suggests that consumers should respond to resource level under this trade-off as well as to predation risk (Abrams 1991, Werner and Anholt 1993). Depending on circumstances activity is predicted to increase or decrease as resource levels decline (Abrams 1991, Werner and Anholt 1993), or, that at low resource levels (energy depleted organisms) consumers should take greater risks to obtain food (Lima 1998a). Thus, changes in resource density in a

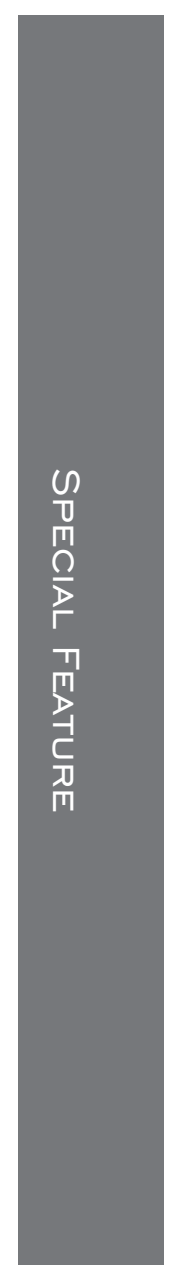


linear food chain should indirectly affect the predator through changes in consumer vulnerability. Such TMIIs therefore should be quite common.

We have conducted two experiments that illustrate this effect. Anholt and Werner (1995) manipulated resources available to anuran larvae and noted that mortality rates due to an odonate predator were 1.6-fold higher at the lower food level. Filming the anuran larvae under similar resource levels indicated that the increase in mortality at low food levels was directly proportional to the increase in activity at this resource level (see also Anholt and Werner 1998). Peacor and Werner (1997) similarly demonstrated that introduction of (larger) competitors caused a $35 \%$ increase in predatory mortality on a (smaller) reacting size class of anuran larvae. Behavioral observations again indicated that activity of the smaller class increased with the addition of the competitors (presumably due to lowered resources). These studies suggest that bottom-up TMIIs could be quite substantial. Despite the obvious symmetry with top-down cascades caused by the common mechanism (growth/risk trade-offs), bottom-up TMIIs have received very little attention. Further, the DMIIs and TMIIs of predators (top-down) on nonadjacent trophic levels are usually parallel because both typically reduce the impact of intervening species on resources. Those effects transmitted up the food web, however, may not be parallel. An increase in resources can increase the production of consumers available to the top predator, but may reduce their activity and therefore the availability of the consumer to the predator. Because bottom-up density- and trait-mediated effects may be in opposite directions, we will need to determine their relative magnitudes in order to understand patterns in net effects.

Theoretical work reinforces these patterns. Abrams (1982, 1984, 1991, 1995) has explored three-species food chains that parallel some of the characteristics of the empirical examples, i.e., where the middle species (consumer) adaptively responds to both its predator and its resource according to a growth/risk trade-off (see also Schmitz 1998b, Diehl et al. 2000). In general, allowing the consumer to respond adaptively has dramatic effects on model predictions of species densities and/or fitness (see also a number of predator-prey models incorporating adaptive responses, e.g., Abrams 1984, Ives and Dobson 1987, Schwinning and Rosenzweig 1990, Crowley and Hooper 1994, Fryxell and Lundberg 1994, 1998, Lima 1998b, Brown et al. 1999). Abrams (1992) further shows that interacting adaptive behaviors of two species in a four-species food chain can change the fundamental sign structure of the predator-prey interaction. These sorts of results are reviewed and developed in other papers in this Special Feature.

The three-species shared-resource web

Now consider the three-species food web where two predators/herbivores share a consumer/resource (Fig. 1e). The classic exploitative competition literature provides abundant evidence for strong indirect effects here that are traditionally interpreted as density mediated. Indirect interactions between the predators/herbivores, however, also can be mediated through changes in traits of the consumer/resource. For example, if the adaptive response (e.g., to reduce vulnerability) of the consumer/resource to the two predators is similar, then addition of one predator can render the other less effective, i.e., the responses are reinforcing. If adaptive responses to the two predators are at variance, then addition of one predator can facilitate the effectiveness of the other. Examples of both types of TMIIs can be found in the literature (see also Sih et al. 1998).

First, consider TMIIs that exhibit the negative effects of one predator on another due to trait responses of prey (e.g., Charnov et al. 1976). Peacor and Werner (1997) have shown that the presence of a nonlethal (caged) odonate predator reduced activity of a larval anuran, which in turn reduced predation rates of another species of odonate predator on the anuran; there was a $22 \%$ increase in survival of green frog larvae in the presence of the caged predator. Crowder et al. (1997) found that survivorship of the fish, spot (Leiostomus xanthurus), was better in the presence of both flounder and bird predation than one would predict based on additive effects of the two predators alone. Spot moved into shallow water in the presence of flounder and aggregated in the presence of birds. The authors speculate that the increased survival with both predators was due to the reduction of flounder effectiveness when birds cause the spot to aggregate.

Now consider TMIIs in which one of the predators has a positive effect on another due to trait responses of the prey. Soluk and Collins (1988) show that, when alone, sculpins and stoneflies had quite low predation rates on Ephemerella mayflies. However, when together, predation rates of sculpins on mayflies nearly doubled, evidently because the mayflies responded to the presence of stoneflies by increasing time on the tops of rocks, which then made them more vulnerable to the sculpin (see also Soluk and Richardson 1997, Eklöv and VanKooten 2001). Similarly, Losey and Denno (1998) showed that predation rates on aphids by foliarfeeding and ground-feeding predators when combined was nearly double the sum of their individual rates. Foliar-feeding predators induced aphids to drop from plants, making them vulnerable to ground-foraging predators. The authors also demonstrated in the field that combined predators had a significantly greater than additive effect on aphid population growth, results that clearly have implications for biological control (Losey and Denno 1998). Swisher et al. (1998) reported an $11 \%$ increase in consumption of larval mayflies by bluegill sunfish in the presence of a dragonfly larva. The authors speculate that the dragonfly caused the mayflies to move, and therefore made them more vulnerable to the fish (interestingly this response was only 
seen at low levels of structural complexity in the environment). A well-known example of this sort of facilitation involves ant-following birds (Willis 1969).

In fact, if we broaden our definition of predator to include parasites, then abundant evidence exists for facilitating effects. Parasites often influence the behavior of hosts, making them vulnerable to predators that can serve as subsequent hosts (Holmes and Bethel 1972, Dobson 1988, Wedekind and Milinski 1996), although clearly this effect has both positive and negative effects on the ultimate host. Induced chemical or morphological responses of plants, e.g., to herbivores (see Karban and Baldwin 1997), also could be transmitted indirectly from one herbivore to another in this web and need to be examined. Muller and Godfray (1999) present a broad discussion of the potential and evidence for TMIIs in parasitoid-host communities. Shiojiri et al. (2001) discuss how the infochemicals originating from cabbage damaged by two herbivore species alter the searching behaviors of their specialist parasitoid wasp in a way that would lead to TMIIs.

\section{The three-species shared-predator web}

Now consider a three-species web where two consumers share a predator (Fig. 1f). In the literature on indirect effects, this is the food web that embodies apparent competition (Holt 1977, Abrams 1987). Although often conceived of as a DMII from one to the other consumer through predator population density, the presence of one prey species clearly can induce changes in predator traits that alter the interaction of the predator with the other prey species.

One of the first experimental demonstrations of "apparent competition" was a TMII illustrating a negative effect through the behavior of predators. Schmitt (1987) demonstrated that the addition of bivalves to plots enhanced predation on gastropods (and areas with higher densities of gastropods led to higher mortality of bivalves) due to aggregation behavior of a guild of predators. Predators were fourfold more common on bivalve enhancement plots, leading to a 1.6-3 fold increase in the fraction of gastrapods killed. Aggregation responses of predators are one of the major mechanisms suggested in the context of apparent competition, and such aggregation responses constitute TMIIs. Similarly, Harmon et al. (2000) experimentally demonstrated that the presence of dandelions, which are a pollen source for a coccinellid beetle, doubled the predation rates of the beetle on aphids in alfalfa, apparently by increasing tenure time of the beetles in local areas.

However, although negative-negative effects are generally expected between prey that share a predator, these effects can readily be either positive or negative. Huang and Sih (1990) demonstrated a positive effect in a system consisting of a fish predator, a salamander, and an isopod (the latter two prey do not compete for resources). In the presence of the isopod, the predation rate on the salamander was only $45 \%$ of that in the absence of the isopod. With isopods available, the fish apparently were more active, which in turn reduced the emergence rate of the salamander from refuges and thereby reduced predation rates on the salamander.

Theory (e.g., Abrams 1987) and other empirical work also suggest that positive interactions between prey species through behavior of the predator should be common. For example, prey switching by predators, due either to search image phenomena or to microhabitat differences in prey distribution, represents a TMII. (Type II functional responses can give the same results, but we do not consider these to be trait mediated unless the functional response is altered by the presence of one of the species.) In this case, presence of one species alters the behavior of the predator, which then has a large impact on the interaction between the predator and the other prey species. Prey switching by predators has been well documented, but typically has not been identified with the larger conceptual issue of TMIIs (see Bolker et al. 2003). Less palatable prey also can reduce the profitability of a patch to a predator and thereby reduce predation pressure on palatable prey (e.g., Wootton 1993).

Abrams (1987, 1990) has shown, in theory, that adaptive behavior of either the predator or the prey in this web can influence the nature of the predator's functional response, which in turn affects instantaneous population growth rates of the prey. Consequently, there are various potential TMIIs in this web that can take on any combination of positive and negative effects. If a changing environment prevents populations from coming to equilibrium, the indirect effects transmitted through the predator's functional responses to other prey can be more important than those transmitted through its density (Abrams 1987).

\section{Nontrophic links and TMIIs}

Thus far we have explored TMIIs due to phenotypic responses associated with trophic links. However, TMIIs can arise from nontrophic links, especially various forms of interference competition.

In a three-species shared-predator web, interference competition can occur between the two prey species (Fig. 1h). The causal path of the TMII here is from one prey to the behavior (or other traits) of the other prey to the predator. For example, a superior interference competitor can exclude another from refuges and thereby increase the vulnerability of the latter to a predator. In the Huang and Sih (1990) study, the interaction between salamanders and (female) isopods is of this type; salamanders reduced refuge use by the isopods, thereby rendering the latter roughly 2.5 times more vulnerable to the fish. Soderback (1994) argues that replacement of a native crayfish in Sweden by an introduced species is largely caused by differential predation from fish (perch). Both species reduce activity and increase their refuge use in the presence of perch, and in single-species experiments do not appear to differ in vulnerabil-

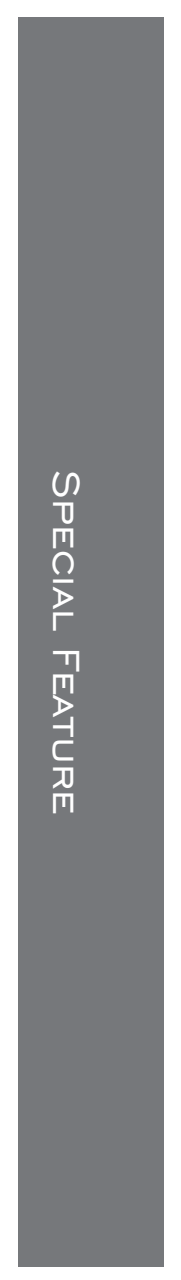


ity. However, when together, perch differentially remove the native species because the invader is dominant in interference competition for shelter (see also McNeely et al. 1990). In a three-species shared-resource web the two predators/consumers can interfere with each other (Fig. 1g) causing a trait-mediated effect on the prey species. Stelzer and Lamberti (1999) suggest that this is one mechanism that may be responsible for higher order effects in an experimental stream food web where the presence of a fish reduces the impact of crayfish on invertebrate prey (see also Eklöv and Werner 2000). It is likely that such effects also occur in cases such as those involving parasitoids, where inferior competitors are deterred by volatiles produced by superior competitors (e.g., Janssen et al. 1995). Interference can be responsible for other types of TMIIs as well. Johansson (1995) demonstrated that an active copepod, through involuntary interactions with a sedentary cladoceran, increased the activity of the cladoceran, which in turn increased encounter rates of the latter with its damselfly predator by 2.5 -fold.

\section{Interactions involving more than two links}

Many examples of TMIIs have been documented in interactions with more than two links. In some cases, this results from measuring the effect several links removed from the reacting species because of difficulties in quantifying the intervening links. The following examples incorporate interactions with three or four links (four or more species, thus aggregating several of the basic TMIIs in Fig. 1), and permit us to discuss interactions that traditionally have been viewed as very important in the ecological literature, e.g., the interaction of competition and predation.

Consider a four-species (diamond) web with a predator, two consumers, and a resource. With this web, we can demonstrate the trait-mediated effects of a predator on competitive interactions among prey species, i.e., how the mere presence of a predator can alter the per capita competitive effects of species on each other. (If the competition is exploitative, this also means that a TMII (trophic cascade) to resources occurred.) For example, we have found that green frog larvae often lower their activity proportionately more than similar-sized bullfrogs in the presence of an odonate predator. Consequently, bullfrogs become relatively better competitors in the presence of the odonate (Werner 1991, Peacor and Werner 1997). This effect is particularly clear when one competitor does not react to the presence of the predator and so garners a greater share of the resources. In a number of experiments, we have shown that the presence of caged predators induces changes in activity and space use of small anuran larvae, which in turn substantially reduces their per capita or unit biomass competitive effects on other (nonreacting) classes (Werner and Anholt 1996, Peacor and Werner 2000, Peacor 2002). Relyea (2000) has shown that caged predators, in fact, can reverse the outcome of competitive interactions between two species of anuran larvae (see also Persson 1991). Importantly, this study also examined both behavioral and morphological responses to predators (and competitors), and there is a suggestion that the morphological responses contributed significantly to the TMII, causing a reversal of competitive effects. Lefcort et al. (1999) also have shown that the presence of a fish cue alters the competitive interactions between tadpoles and snails. Kuhara et al. (1999) manipulated densities of a mayfly and caddisfly in a stream system, demonstrating strong competitive effects. In the presence of fish (sculpin) that were not able to feed on these grazers, however, competitive effects became nondetectable across this gradient of densities. Diel vertical migration of zooplankton also can be mediated behaviorally through the presence of predators or their exudates (e.g., Bollens and Frost 1989, Leibold 1990, Neill 1990, 1992), which may affect interactions between competing species (e.g., Leibold 1991, Leibold and Tessier 1991). Finally, we have evidence that the positive effect of the presence of predators on resources due to responses of consumers may affect species diversity, i.e., an effect that is parallel to the keystone predator effect. Peacor and Werner (1997) show that a TMII from the presence of a caged predator through anuran larvae enabled the invasion of a system by another species (a midge) that was not able to invade in the absence of a cue of the predator.

Because risk to predators decreases with size, smaller size classes of many species of fish are confined by predators to the littoral zones in small lakes; this potentially has far-reaching trait-mediated effects on competitive interactions between these species (see Mittelbach 1981, 1988, Mittelbach and Chesson 1987, Osenberg et al. 1988, 1992, Werner and Hall 1988). Werner et al. (1983) found a 1.2-fold increase in mass gain of larger (invulnerable) bluegill in the presence of largemouth bass because the latter caused smaller bluegill competitors to shift to a poorer but safer (vegetated) habitat. Small bluegill that were consumed by the bass were replaced, and thus the effect on the large class was entirely trait mediated. Many authors have speculated that wholesale changes in community structure of lakes when piscivores were introduced were due, in part, to behavioral shifts of prey fish (e.g., Carpenter et al. 1987, Tonn et al. 1992, Brabrand and Faafeng 1993, Persson et al. 1996, Byström et al. 1998). Large numbers of species undergo habitat shifts during their ontogeny due to size-specific growth/risk trade-offs that will lead to similar TMIIs (Werner and Gilliam 1984).

In a terrestrial example, Abramsky et al. (1998) showed that flying a trained owl over experimental enclosures caused a smaller species of gerbil to shift activity to plots without the owl, regardless of the presence of a larger gerbil species. This behavior dramatically changed estimates of competitive interactions be- 
tween the two gerbil species. Lima and Valone (1991) argued for similar effects of predators on birds. Other studies suggesting that the mere presence of predators (the nonlethal effect) could substantially alter competitive interactions are those of Kohler and McPeek (1989) and Bouskila (1995).

If a second predator is added to the web, differential reactions to these predators may generate important trait-mediated effects on competitive interactions. For example, because bullfrog and green frog larvae differ in their vulnerability to different suites of predators (fish vs. invertebrate predators), they exhibit different spatial responses to these predators (Werner 1992). Fish and invertebrate predators themselves are inversely related because of strong intraguild predation (fish feed on the invertebrate predators; Crowder and Cooper 1982, Werner and McPeek 1994). Due to the differential spatial responses of the two anuran species to these predators, they overlap in habitat use for much of their life cycles in the absence of the fish, whereas they segregate early in their life cycles in the presence of fish (Werner 1992). Further, these responses are size specific and therefore can change over ontogeny (see Eklöv and Werner 2000).

Transmission of TMIIs from a higher trophic level through a species to its competitor also can be due to interference competition. For example, competitive interactions between two ant species appear to be reversed in the presence of a phorid fly, a parasitoid of the soldier caste of one of the species (Feener 1981). The dominant species in the absence of the fly won $63 \%$ of the confrontations at baits. However, in the presence of the fly it won only $13 \%$ of the confrontations. When the fly was present, the soldier class of the dominant species hid in the leaf litter or returned to the nest instead of engaging the competing ants. Orr et al. (1995) provided further experimental evidence for this phenomenon by manipulating the presence of phorid flies (see also Morrison 1999). In the absence of the phorid fly, fire ants always dominated baits over four other genera of ants. In the presence of the fly (a specialist on the fire ants), however, the fire ants hid under seeds, pebbles, and sticks or returned underground, and the other genera of ants dominated the baits. A single fly was sufficient to disrupt recruitment by a colony to baits. Feener (1988) also demonstrated that an ant species that mounted raids on foraging termite workers was similarly affected by the presence of a phorid fly, and this effect would be likely to affect the termite resource or competitors. The cascade to the resource was not documented in these studies, but at the very least, presence of the predator (parasitoid) caused behavioral responses that altered the distribution of resources among competing species. Feener (2000) reviews the literature on parasitoid-mediated competitive interactions in ants and suggests that such TMIIs have widespread and important effects on the composition of ant communities and ant species invasions.

Finally, Raimondi et al. (2000) have provided an excellent example of how traits other than behavior can lead to strong TMIIs. In the system that they studied, a whelk that preys preferentially on acorn barnacles has both a direct predatory effect on the barnacles and induces a "bent morph" if it crawls over juvenile barnacles. The non-induced (conical) morph has a positive effect on recruitment of mussels that compete for space with a brown encrusting alga. The bent morph has a negative effect on recruitment of the mussels, thereby releasing the encrusting alga from competition for space. In areas of high foraging activity of the whelks, the TMII has a dramatic effect on the structure of the community, as demonstrated by whelk exclosures and subsequent reinvasion by the whelks. The authors cite the wide range of taxa showing induced morphological polyphenisms (polymorphisms) and suggest that the resulting TMIIs are likely to be important in many communities. Because this study lasted for 60 months, it is unique in demonstrating the long-term consequences of a TMII rather than short-term effects on components of fitness.

\section{The Effects of Species Densities on Response MEASURES OF TMIIs}

The vast majority of the experiments that we have reviewed simply manipulate presence and absence of a species (usually a predator) that causes trait modifications in a second species, while holding the abundance of the second and other species constant. These experiments can demonstrate that TMIIs are probably important in the study system, but they provide little insight on how the context of these interactions will affect the responses measured to quantify TMIIs. For example, the magnitude of the TMII may be strongly dependent on the consumer (transmitting) species density, as well as densities of the other species involved.

The context dependence of responses is readily understood in relation to three principal processes involved in a TMII with a single trait link (Fig. 1). One species modifies traits in response to changes in the density of another species, this trait modification changes the magnitude of the interaction between the reacting species and a third species, and this change in interaction strength affects fitness measures of the third species. All three of these processes can be strongly affected by food web context. Consequently, studying TMIIs over an environmental or species density gradient can provide added insight into the underlying mechanisms involved in the three processes, and how TMIIs will vary over time and space.

A few studies indicate dose responses of reacting consumer traits to predator or resource density manipulations that would affect any ensuing TMIIs (e.g., Soluk 1993, Diehl 1995, Werner and Anholt 1996, Anholt et al. 2000, Diehl et al. 2000, Peacor and Werner 2001).

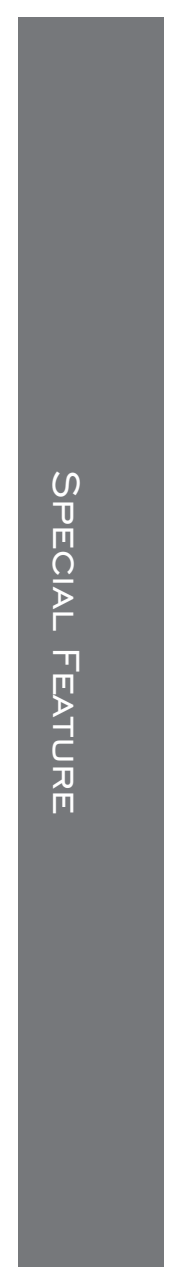


For example, Soluk (1993) examined the functional responses of two stream predators (sculpins and stoneflies) on two different mayfly species at different densities. Functional responses for the two predators when together were significantly different than those predicted from responses when alone, indicating interference between predators with one mayfly species and facilitation with the other species. That is, additive models for predicting combined functional responses did not account for nonlinearities introduced by behavioral reactions between predators and between predators and prey. Moreover, the shapes of the curves were markedly different, with the facilitative effect being maximal at intermediate prey densities and the negative effect being maximal at higher densities. Thus, there are indications that the density of the predator or the resource will affect the magnitude of TMIIs.

Less is known about the effects of transmitting species density on TMIIs. Consider the diamond food web configuration previously examined, in which a predator affects consumer traits reducing the consumer-resource interaction strength, which in turn has a positive effect on resource level and competitor growth rate. We have shown that the magnitude of this positive indirect effect on competitor growth is strongly dependent on species densities (Peacor and Werner 2000). Caged (nonlethal) dragonflies caused a trait-mediated effect on large green frogs (that do not react to the dragonflies) through their effects on traits of small green frog competitors. This TMII varied from negligible to strongly positive as the density of the small green frog (transmitting species) increased (Peacor and Werner 2000; see also Werner and Anholt 1996, VanBuskirk and Yurewicz 1998). The reasons for the density effects are straightforward. At low density, the transmitting species has little effect on resources and therefore little effect on the competitor, even though growth of the transmitting species is reduced in proportion to its reduction in individual foraging effort. At higher densities, the transmitting species has an increasing effect on resources and the reduction in foraging activity leads to an increasing positive indirect effect on resources available to the competitor.

We also have examined the effect of environmental context on the TMII in the diamond configuration by varying nutrient levels, which should affect resource dynamics (Peacor 2002). Using a system similar to that just described, we found that caged dragonfly larvae had a much larger TMII on large (nonreacting) anuran larvae at high than at low nutrient levels. This trend was probably due to two mechanisms: (1) there is likely to be a steeper relationship between resource level and resource growth rate at the higher nutrient level, and (2) the reduction in foraging of small anuran larvae may be more pronounced at higher resource levels.

These phenomena also lead to some interesting effects on the transmitting species growth due to TMIIs reflected on it through resources. Both model and em- pirical results indicate that it is precisely where the relative effect of the predator on the growth rate of the transmitting species is minimal that the TMII on the competitor is maximal and vice versa (Peacor and Werner 2000). The net effect of the predator on growth rate of the transmitting species is the sum of the direct (negative) effect on transmitting species foraging effort and the consequent indirect (positive) effect on resource levels. When the transmitting species is at low density, the negative effect on growth due to reduction in activity dominates the net effect of the predator. In this case, the effect on resources, and therefore the positive effect of the predator on the transmitting species growth rate, is small. However, as transmitting species density increases and effects on resources become more important, the indirect positive effect of the predator on resources becomes more prominent, leading to positive effects on the transmitting species. The net effect of these two opposing processes can be positive or negative on the growth rate of the transmitting species, depending on their relative magnitudes (Peacor 2002). This principle was proposed by Abrams (1987) and was explored theoretically in a number of subsequent papers (Abrams 1992, 1993, Abrams and Rowe 1996).

\section{Comparing the Relative EfFects of DMiIs AND TMIIS}

How important are TMIIs in food webs compared to DMIIs? One might argue, for example, that the density effects of a predator on a consumer would swamp out any trait effects propagated indirectly to other species in the web, even though the latter appear large when density effects are experimentally blocked. Further, density and trait effects are likely to differ in magnitude as the densities of the protagonists change. It may take relatively few predators to elicit strong behavioral responses of an entire population of prey (e.g., Feener 2000), whereas these few predators may have limited effects on density of the prey. However, when predators are dense, they may have large density effects but little additional behavioral effects on prey. This principle should apply to traits other than behavior as well. It is difficult to assess these impacts empirically because density and trait effects are inevitably confounded; e.g., if a predator is introduced to a system, it generally causes both effects. Further, density and trait effects may not have the same sign and therefore have canceling effects, again making it difficult to assess their relative import.

Very few studies provide insight on this issue. The presence (and magnitude) of TMIIs typically has been demonstrated in studies in which the density effect of the agent causing the trait response in a species was blocked or negligible. For example, in the case of a predator, investigators have employed "nonlethal" predators either by presenting cues of the presence of the predator or by disabling its trophic apparatus. In- 
vestigators also have employed systems in which the numerical effect of a predator on a consumer is minimal because of the life history stages used or the effectiveness of the trait response (e.g., refuging). As we have noted earlier, these studies have provided important insights into the nature and mechanisms of traitmediated effects. However, such studies provide little insight into the relative magnitudes or interaction of density and trait effects.

The few studies that have attempted to partition net indirect effects into trait and density components have accomplished this several different ways. Wissinger and McGrady (1993) isolated the TMII in their study of dragonflies and damselflies and assumed that the DMII would be on the order of the density reduction of the intervening species by the top predator. Based on this, the authors argued that the trait effect was over twice the density effect. Huang and Sih (1991) subtracted the density-mediated effect from the total indirect effect to obtain the trait-mediated effect in their study of fish, salamanders, and isopods. They also estimated the effect of the TMII by using the proportional reduction in salamander feeding rates in the presence of fish scent, multiplied by the number of isopods killed by salamanders not in the presence of fish. Both methods employed some unrealistic assumptions, but the authors argued that the estimates were biased in opposite directions, and because they were close, that they gave valid estimates of the relative importance of traitand density-mediated effects. The authors concluded that the trait-mediated effects contributed more strongly to net effects than did the density effects.

We independently manipulated the density and trait effects of a larval odonate predator on a reacting anuran larva and quantified the consequent indirect effects on a nonreacting competing anuran larva (Peacor and Werner 2001). We crossed four levels of trait response by the reacting anuran larva (manipulating the number of caged odonate predators) with three levels of density reduction (hand removal of individuals on an exponential schedule, which thereby causes the predator's density effect without cue of its presence). These treatments allowed us to independently assess the predators' density- and trait-mediated effects on resources and on the (nonreacting) competitor over a wide range of a potential "predator-prey effect space," i.e., where absolute and relative magnitudes of density and trait effects varied. These results then were used to locate the interaction of unrestrained predators (free to prey on the transmitting species) in the predator-prey effect space and to interpret the predator's net indirect effects in the system.

The net indirect effect of the predator through the transmitting species and the resources to the competitor was quite large. Analyses based on the independently assessed TMII and DMII indicated that the density effect of the free predator only accounted for $\sim 14-24 \%$ of the net indirect effects. The remaining $76-86 \%$ was due to the trait effect and an interaction between the trait and density effects (the trait effect was $\sim 38 \%$ of the net effect and the interaction therefore accounted for $38-48 \%$ ). We suspect that, in part, the strong interaction between density- and trait-mediated effects is due to a phenomenaon discussed in the previous section. Both removal and foraging reduction caused by the predator lead to reduced herbivory, and if the resources respond nonlinearly to this reduction, then the resultant increase in resources should be greater than the sum of the isolated effects of the DMIIs and TMIIs. We further employed these results to estimate the relative contributions of density reduction and foraging reduction over the entire predator-prey effect space. This analysis suggested that the effects of TMIIs were very important over most of this space.

The reasons behind the large effect of the TMII in the previous experiment, and why TMIIs generally can be expected to be important, are straightforward. The total impact of the transmitting species on other species in the food web is a function of the density of the transmitting species and the average foraging rate of each individual. The predator causes reductions in both, and these effects are then transmitted to the other species. Over a finite period of time, the foraging reduction due to the presence of the predator is immediate, affects the entire population, and occurs over the entire period of time. Thus, the cumulative trait-mediated effect of the predator over the cohort lifetime can be very significant. Density reduction, in contrast, occurs gradually over time and is transmitted only in proportion to the individuals removed, not the entire population. Thus, in cases in which predators have a substantial impact on the foraging effort of prey, we might expect strong trait-mediated effects and strong modifications of interactions among other species in the web, even when predator effects on prey density ultimately are quite large. We clearly need studies assessing the robustness of these conclusions, but they do suggest that the bias in considering the density effects of predators (and other agents) to the exclusion of their trait-mediated effects has limited our understanding of ecological systems. It is likely that many of the effects traditionally attributed to a predator's consumption of prey in a food web may be caused, at least in part, by their effect on surviving members of the population.

\section{Higher Order Effects due to Alteration of ENVIRONMENTAL CONTEXT}

The presence of a third species also can alter the interaction between two others by affecting the environmental context in which that interaction takes place. This is a different mechanism than the one that we have discussed thus far, but has some of the same consequences and has often been grouped with TMIIs under interaction modifications (Wootton 1993).

For example, by feeding on cladocerans, planktivorous fish release phytoplankton populations, which

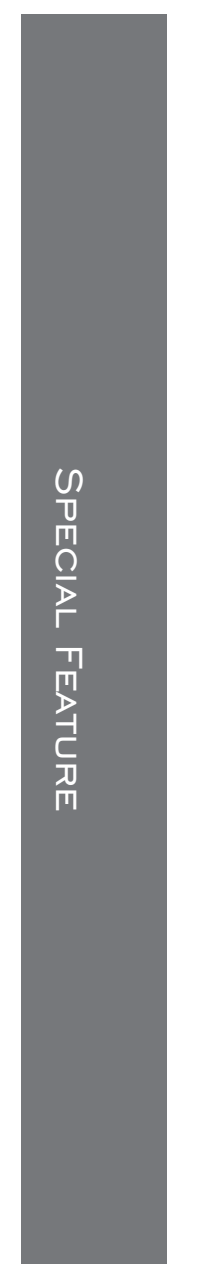


in turn can increase the turbidity of the environment. This increased turbidity could reduce the ability of the plankitovores to detect cladocerans. Thus the indirect effect of the fish on the algae alters the magnitude of the fish-cladoceran interaction via the environmental context. Aquatic plants increase the complexity of the environment and clearly have strong effects on the interactions of predators and prey (e.g., Crowder and Cooper 1982, Power 1990), and any effects of consumers on plant density could affect their vulnerability to predators. Martin et al. (1989) suggest that, in a marine system, complex higher order effects obtained when blue crabs and the fish, spot, were stocked together than when alone arose through the effects of the crab on abundance of the alga Enteromorpha, which provides a refuge for prey of the spot. Wootton (1992, 1993) has shown that the presence of a barnacle changes the background contrast, altering the interaction between gulls and limpets in the intertidal zone (presumably by altering encounter rates). Limpet survival rates were 3-5.4 times greater with barnacles present than in their absence (Wootton 1993). Wootton et al. (J. T. Wootton, M. E. Power, J. M. Chase, and M. S. Parker, unpublished manuscript) also show that increasing algae in streams altered the visual and mechanical environment, making prey less vulnerable to predators and thereby changing food chain dynamics. Wahl et al. (1997) demonstrate that epibionts growing on the surface of organisms can drastically alter their susceptibility to both herbivores and carnivores. Epibionts can either attract or repel consumers and their effect can be strong enough to switch host positions on preference gradients (Wahl et al. 1997).

In these examples, the action of a species or guild of species alters some aspect of the environmental context of an interaction between other species, which changes the strength of that interaction. This type of modification of the interaction between two species also is likely to be important and widespread. This effect has the same conceptual import as the TMIIs: the presence of a third species alters the per capita effects of two other species on each other, creating higher order interactions. However, the fundamental mechanism differs. Instead of a species causing a phenotypic change in a second species, which then affects the latter's impact on yet other species, in this case a species affects the environmental context of the interaction occurring between two other species. It is likely that in our quest to model these systems, this fundamental difference in mechanism will be critical to incorporate and will have different consequences for system dynamics. This concern indicates the importance of a clean terminology for this area that will enable us to clearly see the differences in implications of these different types of interactions.

\section{CONCLUSIONS}

Ecologists have elaborated a large body of theory on species interactions, food web structure, and commu- nity properties that is founded on the proposition that one species affects another by changing its density, and these effects then can be transmitted indirectly to other species in the food web. Many of the properties that define ecological communities can be seen to emerge from these indirect effects (e.g., diversity through keystone predator effects, presence of trophic cascades). Consequently, there is a venerable tradition of attempting to isolate and characterize the interaction between two species, and then attempting to understand the ramifications of this interaction when embedded in a larger community. In such "fixed-property" webs (Abrams 1996), an ordered list of transmitting species specifies a unique indirect effect, because effects are transmitted by changes in densities of intervening species (e.g., Yodzis 1988, Schoener 1993).

The literature that we have just reviewed indicates that this approach clearly will be inadequate for many systems. We have begun to appreciate that one species' effect on another's traits can be transmitted indirectly to other elements of the food web and can be of the same order of magnitude as the density effects. That is, the strength of the interaction between two species now depends dynamically on background community composition, and these changes will be reflected in the larger structure of the system. If species traits are plastic, pairwise per capita interaction effects are not simply functions of the densities of the two species, the food web cannot be treated as having "fixed properties," and indirect effects through a set of transmitting species are no longer uniquely specified. In fact, intervening species can transmit indirect effects via density and trait changes that are of different sign, and thus there may be more than one chain of effects involving the identical sequence of transmitting species. Further, strong TMIIs are evident in a very wide array of taxa and systems, both aquatic and terrestrial. Virtually all of the interactions that ecologists routinely consider (competition, predator/victim, mutualism, parasitism, keystone predator phenomena, trophic cascades, apparent competition, and intraguild interactions) can be influenced or caused by TMIIs.

Although there has been a long history of interest in the question of higher order (such as trait) effects in communities (e.g., Vandermeer 1969; see the 1994 Special Feature in Ecology 75(6)), these concerns have not led to a focused research program. This would appear to reflect, in part, the limitations of approaches taken that have emphasized defining higher order interactions and addressing how they can be statistically detected and quantified (e.g., Wilbur 1972, Neill 1974, Morin et al. 1988, Wilbur and Fauth 1990, Worthen and Moore 1991; see the 1994 Special Feature in Ecology 75(6)). Statistically identifying higher order effects can be a useful first step, but ultimately is an ambiguous and unsatisfying way to proceed. Such analyses conflate a number of problems or processes: for example, the inappropriate application of statistical tests, intraspecific 
density dependence, or the exclusion of relevant food web elements (Case and Bender 1981, Pomerantz 1981, Yodzis 1988, Billick and Case 1994, Menge 1994, Wootton 1994, Abrams et al. 1996). Most important, such approaches skirt the fundamental issue of how these higher order effects can be incorporated into a biologically faithful model of dynamics of the system. Directly examining mechanisms can be a much more powerful approach. For example, we can evaluate the potential for higher order effects directly from knowledge available at the individual level that can be used to generate explicit predictions concerning the higher order effects. Focusing on the mechanism has the additional benefit of integrating different fields or levels of investigation. For example, behavioral ecological theory can provide the mechanistic foundation for models of many of the phenomena that we have discussed.

There are a number of significant lacunae in our knowledge of the effects of phenotypic plasticity in traits on ecological communities that would repay investigation and we will now list some of these.

1) We have only one study that cleanly separates the density and trait components of an indirect effect and evaluates their relative magnitudes. This separation to elucidate the mechanisms and to begin assessing their relative importance is essential. However, in the long run, such a focus can be counterproductive if limited to this question, i.e., by dichotomizing effects in an artificial manner (witness the unproductive controversies attempting to determine the relative importance of competition vs. predation and top-down vs. bottom-up effects). Ultimately, we need to understand how density and trait effects interact so that this interaction can be incorporated in dynamic models.

2) Most of the evidence for the strength of trait effects comes from experiments with predators (where only cue of predator presence is provided) and where TMIIs are caused by behavioral responses. We clearly need studies examining the effects of plasticity in other traits (morphological, physiological, life historical) on species interactions as well as effects due to agents other than predators.

3) The empirical literature provides little insight on the long-term impact of TMIIs, i.e., through population dynamic responses (but see Schmitz 1998b, Raimondi et al. 2000). Most of the available experiments on TMIIs assess short-term responses on some component of fitness (e.g., individual growth), although experiments examining population responses should be practical to conduct with organisms such as Daphnia or protozoa that exhibit both a range of induced responses and rapid turnover. For example, Boeing et al. (W. J. Boeing, B. Wissel, and C. W. Ramcharan 2001 ESA Abstracts) report that when reacting and nonreacting clones of Daphnia were exposed to predators, the reacting clone exhibited more stable population densities, higher energy flow rates through the food web, and the highest sustained predator biomass. Further, short-term experiments are potentially biased in favor of demonstrating strong TMIIs if responding species overreact to a manipulation introducing predators or predator cues. That is, the optimal response to initial detection of predators or change in predator density may be to drastically reduce activity or retreat to refuges until the danger passes or is more effectively assessed (Abrams 1991, Lima and Bednekoff 1999). In this case, the measured TMIIs may be larger than they would be if the experiments were conducted over longer time periods.

4) Studies of TMIIs need to be extended to address the larger issues in community ecology. For example, we demonstrated that invasion of a system by a species was made possible by the nonlethal presence of a predator (Peacor and Werner 1997). Consequently, it appears that TMIIs can affect community diversity (by a mechanism similar to that of the keystone predator phenomenon).

5) Consideration of TMIIs raises many important issues concerning the time scales of ecological studies. When traits are plastic, they may change at rates that are orders of magnitude faster (e.g., behavior) or slower (evolution) than the rates of change of population densities. Many trait effects will be on the same time scale as the direct density effects of one species on another; thus, it is more difficult to devise experiments to separate these effects. Consequently, traditional approaches to reducing the dimensionality of these systems by abstracting components of the system that are on different times scale can be less effective. For example, one can abstract fish population dynamics (generation time in years) when examining the interaction of fish and zooplankton (generation time in weeks). However, the effect of zooplankton density on fish traits, particularly behavior, can be immediate and highly dynamic. Further, different phenotypic responses (e.g., behavior, morphology) can occur over different time scales and will differ in reversibility.

6) We need to conduct our experiments over gradients of densities of both those species inducing the trait changes and those transmitting them. Results from initial studies indicate some important and nonintuitive aspects of transmission of trait effects with densities of the transmitting species (e.g., Peacor and Werner 2000). The relationships between the density of species and their trait effects will be necessary to build theory and to model these interactions; presence-absence experiments tend to focus attention on detecting phenomena and not on the functional properties of the interaction. Focusing on the functional properties also will help to merge theoretical and empirical work in this area.

7) We have little systematic insight regarding when or where TMIIs are likely to be important. Certain patterns suggest that DMIIs may be relatively more important when species lack a significant evolutionary history. For example, the large literature on the effects of fish manipulations on aquatic communities con-

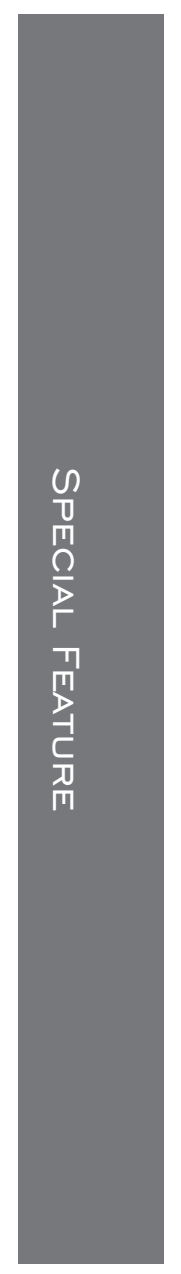


tained a mixture of apparently strong and weak effects that was confusing until it was recognized that the strong effects occurred when fish were introduced to ponds or lakes where they typically were not found (e.g., Wellborn and Robinson [1991]; see also Brooks and Dodson [1965], Wellborn et al. [1996], and Wissinger et al. [1999] for a related argument where salamanders were the predator). When fish were manipulated in communities where they were normally found, the density effects were much less dramatic. It is in the latter communities where we might expect trait-mediated effects to be relatively more important.

8) It is very important that predictions of the theory be made operational and accessible to empirical test so that progress can be made. Theoretical and empirical work on TMIIs traditionally have had somewhat different agendas and focus on different aspects of the problem. Similarly, empirical workers must take more care to focus on the functional relations required in the theory rather than simply documenting the presence of a phenomenon. In general, attention to the quantification of interaction coefficients in ecological systems from a mechanistic perspective would aid both our understanding of the roles of trait and density effects and the interaction of empirical and theoretical work.

9) We need to explore these questions in more complex communities. Relatively few studies have documented the responses of prey to the simultaneous presence of different predators and how this affects traitmediated interactions. Further, we have not yet differentiated cases in which one link in the chain of indirect effects is trait mediated from cases in which multiple links are trait mediated. Most of the examples that we have reviewed show an initial direct effect on a trait of a reacting species that is transmitted to a third species via the direct consumptive or density effect of the reacting species. However, if a predator induces a species to reduce foraging activity directed at a third species, this may cause the latter to become more active or spend more time out of refuges. The change in the third species' traits then could indirectly affect a fourth species. In this case, two successive linkages are trait mediated. Huang and Sih (1990) present one of the few cases in which several linkages were behavioral and led to a change in a density effect. It is not clear if such linkages will introduce different dynamics to systems and, if so, how they should be classified.

10) Peacor and Werner (2001) develop the notion of a predator-prey effect space: any predator-prey interaction can be located in a space whose axes are the trait effect and the density effect of the predator in this interaction. It would be very informative to contrast dynamics in systems that lie in different parts of this space. Further, it would be useful to know how predator-prey interactions are distributed in this space and whether there are taxonomic or system biases in this distribution. This knowledge would help greatly in as- sessing the question of where we could expect TMIIs and in estimating their potential magnitude.

11) The evolutionary implications of these interactions are virtually unexplored (but see Matsuda et al. 1996). Further, both phenotypic and evolutionary responses are, of course, often reciprocal (see Agrawal [2001] for a discussion of this reciprocity) and these responses have been little examined in the context of TMIIs.

In summary, the growing body of empirical evidence suggests that TMIIs are a widespread and important influence in ecological food webs and that recognition of their role will substantially further our understanding of community dynamics and structure. We expect that trait-mediated effects contribute strongly to many phenomena that traditionally have been attributed solely to density effects in species interactions. The existence of these strong TMIIs clearly signals the dependence of interaction magnitudes of species pairs on other species in the community; i.e., that higher order interactions will influence the outcome of many species interactions. Examination of trait-mediated effects provides a fundamental link to the mechanisms of these species interactions. Traits determine performance in species interactions and are direct targets of natural selection. Thus, studies focused at this juncture should contribute to the quest to quantify interaction strengths (e.g., Laska and Wootton 1998, Berlow et al. 1999, Abrams 2001) and foster productive work at the interface between ecological and evolutionary phenomena.

\section{ACKNOWLEDGMENTS}

We wish to thank the following colleagues for reading and critiquing this paper: Peter Abrams, Fred Adler, Peter Eklöv, Locke Rowe, Oswald Schmitz, and an anonymous reviewer. We also wish to acknowledge the support of NSF grants DEB9615523 and DEB-0089809 to E. E. Werner and S. D. Peacor and NCEAS for supporting the working group on TMIIs. This is NOAA GLERL contribution number 1222 .

\section{Literature Cited}

Abrams, P. A. 1982. Functional responses of optimal foragers. American Naturalist 120:382-390.

Abrams, P. A. 1984. Foraging time optimization and interactions in food webs. American Naturalist 124:80-96.

Abrams, P. A. 1987. Indirect interactions between species that share a predator: varieties of indirect effects. Pages 38-54 in W. C. Kerfoot and A. Sih, editors. Predation: direct and indirect impacts on aquatic communities. University Press of New England, Hanover, New Hampshire, USA.

Abrams, P. A. 1990. The effects of adaptive behavior on the type-2 functional response. Ecology 71:877-885.

Abrams, P. A. 1991. Strengths of indirect effects generated by optimal foraging. Oikos 62:167-176.

Abrams, P. A. 1992. Predators that benefit prey and prey that harm predators - unusual effects of interacting foraging adaptations. American Naturalist 140:573-600.

Abrams, P. A. 1993. Indirect effects arising from optimal foraging. Pages 255-279 in H. Kawanabe, J. E. Cohen, and K. Iwasaki, editors. Mutualism and community organization: behavioral, theoretical, and food web approaches. Oxford University Press, Oxford, UK. 
Abrams, P. A. 1995. Implications of dynamically variable traits for identifying, classifying and measuring direct and indirect effects in ecological communities. American Naturalist 146:112-134.

Abrams, P. A. 1996. Dynamics and interactions in food webs with adaptive foragers. Pages 113-121 in G. Polis and K. Winemiller, editors. Food webs: dynamics and structure. Chapman and Hall, New York, New York, USA.

Abrams, P. A. 2001. Describing and quantifying interspecific interactions: a commentary on recent approaches. Oikos 94:209-218.

Abrams, P. A., B. A. Menge, G. G. Mittelbach, D. Spiller, and P. Yodzis. 1996. The role of indirect effects in food webs. Pages 371-395 in G. Polis and K. Winemiller, editors. Food webs: dynamics and structure. Chapman and Hall, New York, New York, USA.

Abrams, P. A., and L. Rowe. 1996. The effects of predation on the age and size of maturity of prey. Evolution 50:10521061 .

Abramsky, Z., M. L. Rosenweig, and A. Subach. 1998. Do gerbils care more about competition or predation? Oikos 83:75-84.

Agrawal, A. A. 2001. Phenotypic plasticity in the interactions and evolution of species. Science 294:321-326.

Anholt, B. R., and E. E. Werner. 1995. Interaction between food availability and predation mortality mediated by adaptive behavior. Ecology 76:2230-2234.

Anholt, B. R., and E. E. Werner. 1998. Predictable changes in predation mortality as a consequence of changes in food availability and predation risk. Evolutionary Ecology 12. $729-738$

Anholt, B. R., E. E. Werner, and D. K. Skelly. 2000. Effect of food and predators on the activity of four larval ranid frogs. Ecology 81:3509-3521.

Beckerman, A. P., M. Uriarte, and O. J. Schmitz. 1997. Experimental evidence for a behavior-mediated trophic cascade in a terrestrial food chain. Proceedings of the National Academy of Sciences (USA) 94:10735-10738.

Berlow, E. L., S. A. Navarrete, C. J. Briggs, M. A. Power, and B. A. Menge. 1999. Quantifying variation in the strengths of species interactions. Ecology 80:2206-2224.

Billick, I., and T. J. Case. 1994. Higher order interactions in ecological communities: what are they and how can they be detected? Ecology 75:1529-1543.

Bolker, B., M. Holyoak, V. Krivan, L. Rowe, and O. Schmitz. 2003. Connecting theoretical and empirical studies of traitmediated interactions. Ecology 84:1101-1114.

Bollens, S. M., and B. W. Frost. 1989. Predator-induced diel vertical migration in a planktonic copepod. Journal of Plankton Research 11:1047-1065.

Bouskila, A. 1995. Interactions between predation risk and competition: a field study of kangaroo rats and snakes. Ecology 76:165-178.

Brabrand, A., and B. Faafeng. 1993. Habitat shift in roach (Rutilus rutilus) induced by pikeperch (Stizostedion lucioperca) introduction-predation risk versus pelagic behavior Oecologia 95:38-46.

Bronmark, C., and J. G. Miner. 1992. Predator-induced phenotypical change in body morphology in crucian carp. Science 258: $1348-1350$.

Brooks, J. L., and S. Dodson. 1965. Predation, body size, and composition of the zooplankton. Science 150:28-35.

Brown, J. S., J. W. Laundre, and M. Gurung. 1999. The ecology of fear: optimal foraging, game theory, and trophic interactions. Journal of Mammalogy 80:385-399.

Bystöm, P., L. Persson, and E. Wahlström. 1998. Competing predators and prey: juvenile bottlenecks in whole-lake experiments. Ecology 79:2153-2167.

Carpenter, S. R., J. F. Kitchell, J. R. Hodgson, P. A. Cochran, J. J. Elser, M. M. Elser, D. M. Lodge, C. Kretchmer, and
X. He. 1987. Regulation of lake primary productivity by food web structure. Ecology 68:1863-1876.

Case, T. J., and E. A. Bender. 1981. Testing for higher order interactions. American Naturalist 118:920-929.

Charnov, E. L., G. H. Orians, and K. Hyatt. 1976. Ecological implications of resource depression. American Naturalist 110:247-259.

Crowder, L. B., and W. E. Cooper. 1982. Habitat structural complexity and the interaction between bluegills and their prey. Ecology 63:1802-1813.

Crowder, L. B., D. D. Squires, and J. A. Rice. 1997. Nonadditive effects of terrestrial and aquatic predators on juvenile estuarine fish. Ecology 78:1796-1804.

Crowley, P. H., and K. R. Hopper. 1994. How to behave around cannibals-a density-dependent dynamic game. American Naturalist 143:117-154.

Diehl, S. 1995. Direct and indirect effects of omnivory in a littoral lake community. Ecology 76:1727-1740.

Diehl, S., S. D. Cooper, K. W. Kratz, R. M. Nisbet, S. K. Roll, S. W. Wiseman, and T. M. Jenkins. 2000. Effects of multiple, predator-induced behaviors on short-term producer-grazer dynamics in open systems. American Naturalist 156:293-313.

Dobson, A. P. 1988. The population biology of parasite-induced changes in host behavior. Quarterly Review of Biology 63:139-165.

Eklöv, P., and T. VanKooten. 2001. Facilitation among piscivorous predators: effects of prey habitat use. Ecology 82:2486-2494.

Eklöv, P., and E. E. Werner. 2000. Multiple predator effects on size-dependent behavior and mortality of two species of anuran larvae. Oikos 88:250-258.

Feener, D. H. 1981. Competition between ant species: outcome controlled by parasitic flies. Science 214:815-817.

Feener, D. H. 1988. Effects of parasites on foraging and defense behavior of a termitophagus ant, Pheidole titanis Wheeler (Hymenoptera: Formicidae). Behavioral Ecology and Sociobiology 22:421-427.

Feener, D. H. 2000. Is the assembly of ant communities mediated by parasitoids? Oikos 90:79-88.

Forrester, G. E., T. L. Dudley, and N. B. Grimm. 1999. Trophic interactions in open systems: effects of predators and nutrients on stream food chains. Limnology and Oceanography 44:1187-1197.

Fritz, R. S. 1983. Ant protection of a host plant's defoliator: consequence of an ant-membracid mutualism. Ecology 64: 789-797.

Fryxell, J. M., and P. Lundberg. 1994. Diet choice and predator-prey dynamics. Evolutionary Ecology 8:407-421.

Fryxell, J. M., and P. Lundberg. 1998. Individual behavior and community dynamics. Chapman and Hall, New York, New York, USA.

Gastreich, K. R. 1999. Trait-mediated indirect effects of a theridiid spider on an ant-plant mutualism. Ecology 80: 1066-1070.

Gelwick, F. P. 2000. Grazer identity changes the spatial distribution of cascading trophic effects in stream pools. Oecologia 125:573-583.

Haemig, P. D. 1999. Predation risk alters interactions among species: competition and facilitation between ants and nesting birds in a boreal forest. Ecology Letters 2:178-184.

Harmon, J. P., A. R. Ives, J. E. Losey, A. C. Olson, and K. S. Rauwald. 2000. Coleomegilla maculata (Coleoptera: Coccinellidae) predation on pea aphids promoted by proximity to dandelions. Oecologia 125:543-548.

Harvell, C. D. 1990. The ecology and evolution of inducible defenses. Quarterly Review of Biology 65:323-340.

Holmes, J. C., and W. M. Bethel. 1972. Modification of intermediate host behavior by parasites. Zoological Journal of the Linnean Society 51:123-149.

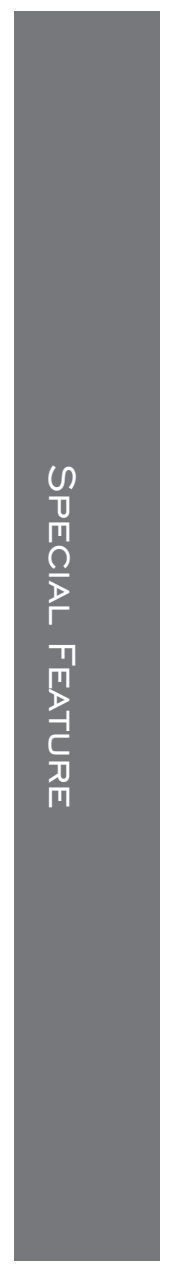


Holt, R. D. 1977. Predation, apparent competition, and the structure of prey communities. Theoretical Population Biology 12:197-229.

Huang, C. F., and A. Sih. 1990. Experimental studies on behaviorally mediated, indirect interactions through a shared predator. Ecology 71:1515-1522.

Huang, C. F., and A. Sih. 1991. Experimental studies on direct and indirect interactions in a three trophic-level stream system. Oecologia 85:530-536.

Ives, A. R., and A. P. Dobson. 1987. Antipredator behavior and the population dynamics of simple predator-prey systems. American Naturalist 130:431-447.

Janssen, A., J. J. M. vanAlfen, M. W. Sabelis, and K. Bakker. 1995. Odor-mediated avoidance of competition in Drosophila parasitoids - the ghost of competition. Oikos 73: 356-366.

Johansson, F. 1995. Increased prey vulnerability as a result of prey-prey interactions. Hydrobiologia 308:131-137.

Karban, R., and I. Baldwin. 1997. Induced responses to herbivory. University of Chicago Press, Chicago, Illinois, USA.

Kohler, S. L., and M. A. McPeek. 1989. Predation risk and the foraging behavior of competing stream insects. Ecology 70:1811-1825.

Kuhara, N., S. Nakano, and H. Miyasaka. 1999. Interspecific competition between two stream insects grazers mediated by non-feeding predatory fish. Oikos 87:27-35.

Laska, M. S., and J. T. Wootton. 1998. Theoretical concepts and empirical approaches to measuring interaction strength. Ecology 79:461-476.

Lefcort, H., S. M. Thomson, E. E. Cowles, H. L. Harowicz, B. M. Livaudais, W. E. Roberts, and W. F. Ettinger. 1999. Ramifications of predator avoidance: predator and heavymetal-mediated competition between tadpoles and snails. Ecological Applications 9:1477-1489.

Leibold, M. A. 1990. Resources and predators can affect the vertical distributions of zooplankton. Limnology and Oceanography 35:938-944.

Leibold, M. A. 1991. Trophic interactions and habitat segregation between competing Daphnia species. Oecologia 86:510-520.

Leibold, M. A., and A. J. Tessier. 1991. Contrasting patterns of body size for Daphnia species that segregate by habitat. Oecologia 86:342-348.

Levins, R. 1968. Evolution in changing environments. Princeton University Press, Princeton New Jersey, USA.

Lewontin, R. 2000. The triple helix: gene, organism and environment. Harvard University Press, Cambridge, Massachusetts, USA.

Lima, S. L. 1998a. Stress and decision making under the risk of predation: recent developments from behavioral, reproductive, and ecological perspectives. Advances in the Study of Behavior 27:215-290.

Lima, S. L. 1998b. Nonlethal effects in the ecology of predator-prey interactions. What are the ecological effects of anti-predator decision-making? BioScience 48:25-34.

Lima, S. L., and P. A. Bednekoff. 1999. Temporal variation in danger drives antipredator behavior: the predation risk allocation hypothesis. American Naturalist 153:649-659.

Lima, S. L., and T. J. Valone. 1991. Predators and avian community organization: an experiment in a semi-desert grassland. Oecologia 86:105-112.

Losey, J. E., and R. F. Denno. 1998. Positive predator-predator interactions: enhanced predation rates and synergistic suppression of aphid populations. Ecology 79:2143-2152.

MacArthur, R. H. 1972. Geographical ecology: patterns in the distribution of species. Harper and Row, New York, New York, USA.

Martin, T. H., R. A. Wright, and L. B. Crowder. 1989. Nonadditive impact of blue crabs and spot on their prey assemblages. Ecology 70:1935-1942.
Matsuda, H., M. Hori, and P. A. Abrams. 1996. Effects of predator-specific defense on biodiversity and community complexity in two-trophic-level communities. Evolutionary Ecology 10:13-28.

McCollum, S. A., and J. VanBuskirk. 1996. Costs and benefits of a predator-induced polyphenism in the gray treefrog Hyla chrysoscelis. Evolution 50:583-593.

McIntosh, A. R., and C. R. Townsend. 1996. Interactions between fish, grazing invertebrates and algae in a New Zealand stream: a trophic cascade mediated by fish induced changes to grazer behaviour? Oecologia 108:174-181.

McNeely, D. L., B. N. Futrell, and A. Sih. 1990. An experimental study on the effects of crayfish on the predatorprey interaction between bass and sculpin. Oecologia 85: 69-73.

Menge, B. A. 1994. Indirect effects in marine rocky intertidal interaction webs: pattern and importance. Ecological Monographs 65:21-74.

Messina, F. J. 1981. Plant protection as a consequence of an ant-membracid mutualism: interactions on goldenrod (Solidago sp.). Ecology 62:1433-1440.

Miller, T. E., and W. C. Kerfoot. 1987. Redefining indirect effects. Pages 33-37 in W. C. Kerfoot and A. Sih, editors. Predation: direct and indirect impacts on aquatic communities. University Press of New England, Hanover, New Hamsphire, USA.

Mittelbach, G. G. 1981. Foraging efficiency and body size: a study of optimal diet and habitat use by bluegills. Ecology 62:1370-1386.

Mittelbach, G. G. 1988. Competition among refuging sunfishes and effects of fish density on littoral zone invertebrates. Ecology 69:614-623.

Mittelbach, G. G., and P. L. Chesson. 1987. Indirect effects on fish populations. Pages 315-332 in W. C. Kerfoot and A. Sih, editors. Predation: direct and indirect impacts on aquatic communities. University of New England Press, Hanover, New Hampshire, USA.

Moran, M. D., T. P. Rooney, and L. E. Hurd. 1996. Top-down cascade from a bitrophic predator in an old-field community. Ecology 77:2219-2227.

Morin, P. J., S. P. Lawler, and E. A. Johnson. 1988. Competition between aquatic insects and vertebrates: interaction strength and higher order interactions. Ecology 69:14011409.

Morrison, L. W. 1999. Indirect effects of phorid fly parasitoids on the mechanisms of interspecific competition among ants. Oecologia 121:113-122.

Muller, C. B., and H. C. Godfray. 1999. Indirect interactions in aphid-parasitoid communities. Research in Population Ecology 41:93-106.

Neill, W. E. 1974. The community matrix and interdependence of the competition coefficients. American Naturalist 108:399-408.

Neill, W. E. 1990. Induced vertical migration in copepods as a defence against invertebrate predation. Nature 345:524526.

Neill, W. E. 1992. Population variation in the ontogeny of predator-induced vertical migration of copepods. Nature 356:54-57.

Nystrom, P., and K. Abjornsson. 2000. Effects of fish chemical cues on the interactions between tadpoles and crayfish. Oikos 88:181-190.

Oksanen, L., S. D. Fretwell, J. Arruda, and P. Niemela. 1981. Exploitation ecosystems in gradients of primary productivity. American Naturalist 118:240-261.

Orr, M. R., S. H. Selke, W. W. Benson, and L. E. Gilbert. 1995. Flies suppress fire ants. Nature 373:292-293.

Osenberg, C. W., G. G. Mittelbach, and P. C. Wainwright. 1992. Two-stage life histories in fish: the interaction be- 
tween juvenile competition and adult performance. Ecology 73:255-267.

Osenberg, C. W., E. E. Werner, G. G. Mittelbach, and D. J. Hall. 1988. Growth patterns in bluegill (Lepomis macrochirus) and pumpkinseed (L. gibbosus) sunfish: environmental variation and the importance of ontogenetic niche shifts. Canadian Journal of Fisheries and Aquatic Sciences 45:17-26.

Paine, R. T. 1966. Food web complexity and species diversity. American Naturalist 100:65-75.

Peacor, S. D. 2002. Positive effects of predators on prey growth rate through induced modifications of prey behavior. Ecology Letters 5:77-85.

Peacor, S. D., and E. E. Werner. 1997. Trait-mediated indirect interactions in a simple aquatic food web. Ecology 78: 1146-1156.

Peacor, S. D., and E. E. Werner. 2000. The effects of a predator on an assemblage of consumers through induced changes in consumer foraging behavior. Ecology 81:19982010.

Peacor, S. D., and E. E. Werner. 2001. The contribution of trait-mediated indirect effects to the net effects of a predator. Proceedings of the National Academy of Sciences (USA) 98:3904-3908.

Peckarsky, B. L., and A. R. McIntosh. 1998. Fitness and community consequences of avoiding multiple predators. Oecologia 113:565-576.

Persson, L. 1991. Behavioral response to predators reverses the outcome of competition between species. Behavioral Ecology and Sociobiology 28:101-105.

Persson, L., J. Andersson, E. Wahlstrom, and P. Eklöv. 1996. Size-specific interactions in lake systems: predator gape limitation and prey growth rate and mortality. Ecology 77: 900-911.

Persson, L., L. Johansson, G. Andersson, S. Diehl, and S. F. Hamrin. 1993. Density dependent interactions in lake ecosystems - whole lake perturbation experiments. Oikos 66 : 193-208.

Pomerantz, M. J. 1981. Do "higher-order interactions" in competitive systems really exist? American Naturalist 117: 583-591.

Power, M. E. 1990. Resource enhancement by indirect effects of grazers: armored catfish, algae, and sediment. Ecology 71:897-904.

Power, M. E., W. J. Mathews, and A. J. Stewart. 1985. Grazing minnows, piscivorous bass, and stream algae: dynamics of a strong interaction. Ecology 66:1448-1456.

Pusenius, J., and R. S. Ostfeld. 2000. Effects of stoat's presence and auditory cues indicating its presence on tree seedling predation by meadow voles. Oikos 91:123-130.

Raimondi, P. T., S. E. Forde, L. F. Delph, and C. M. Lively. 2000. Processes structuring communities: evidence for trait-mediated indirect effects through induced polymorphisms. Oikos 91:353-361.

Relyea, R. A. 2000. Trait-mediated indirect effects in larval anurans: reversing competition with the threat of predation. Ecology 81:2278-2289.

Relyea, R. A. 2001. Morphological and behavioral plasticity of larval anurans in response to different predators. Ecology 82:541-554.

Relyea, R. A., and E. E. Werner. 2000. Morphological plasticity in four larval anurans distributed along an environmental gradient. Copeia 2000:178-190.

Rothley, K. D., O. J. Schmitz, and J. L. Cohon. 1997. Foraging to balance conflicting demands: novel insights from grasshoppers under predation risk. Behavioral Ecology 8: 551-559.

Schlichting, C. D., and M. Pigliucci. 1998. Phenotypic evolution: a reaction norm perspective. Sinauer Associates, Sunderland, Massachusetts, USA.
Schmitt, R. J. 1987. Indirect interactions between prey: apparent competition, predator aggregation, and habitat segregation. Ecology 68:1887-1897.

Schmitz, O. J. 1998a. Direct and indirect effects of predation and predation risk in old-field interaction webs. American Naturalist 151:327-342.

Schmitz, O. J. 1998b. Combining field experiments and individual-based modeling to identify the dynamically relevant organizational scale in a field system. Oikos 89:471184.

Schmitz, O. J., A. Beckerman, and K. M. O'Brien. 1997. Behaviourally mediated trophic cascades: effects of predation risk on food web interactions. Ecology 78:13881399.

Schoener, T. W. 1993. On the relative importance of direct versus indirect effects in ecological communities. Pages 365-411 in H. Kawanabe, J. E. Cohen, and K. Iwasaki, editors. Mutualisms and community organization. Oxford University Press, Oxford, UK.

Schwinning, S., and M. L. Rosenzweig. 1990. Periodic oscillations in an ideal-free predator-prey system. Oikos 59: 85-91.

Shiojiri, K., J. Takabayashi, and S. Yano. 2001. Infochemically mediated tritrophic interaction webs on cabbage plants. Population Ecology 43:23-29.

Sih, A., G. Enlund, and D. Wooster. 1998. Emergent impacts of multiple predators on prey. Trends in Ecology and Evolution 13:350-355.

Soderback, B. 1994. Interactions among juveniles of two fresh-water crayfish species and a predatory fish. Oecologia 100:229-235.

Soluk, D. A. 1993. Multiple predator effects: predicting combined functional response of stream fish and invertebrate predators. Ecology 74:219-225.

Soluk, D. A., and N. C. Collins. 1988. Synergistic interactions between fish and stoneflies: facilitation and interference among stream predators. Oikos 52:94-100.

Soluk, D. A., and J. S. Richardson. 1997. The role of stoneflies in enhancing growth of trout: a test of the importance of predator-predator facilitation within a stream community. Oikos 80:214-219.

Stamp, N. E., and M. D. Bowers. 1993. Presence of predatory wasps and stinkbugs alters foraging behavior of cryptic and non-cryptic caterpillars on plantain (Plantago lanceolata). Oecologia 95:376-384.

Stearns, S. C. 1989. The evolutionary significance of phenotypic plasticity. Phenotypic sources of variation among organisms can be described by developmental switches and reaction norms. Bioscience 39:436-445.

Stelzer, R. S., and G. A. Lamberti. 1999. Independent and interactive effects of crayfish and darters on a stream benthic community. Journal of North American Benthological Society 18:524-532.

Swisher, B. J., D. A. Soluk, and D. H. Wahl. 1998. Nonadditive predation in littoral habitats: influences of habitat complexity. Oikos 81:30-37.

Tilman, D. 1990. Constraints and tradeoffs: toward a predictive theory of competition and succession. Oikos 58:315

Tollrian, R., and C. D. Harvell. 1999. The ecology and evolution of inducible defenses. Princeton University Press, Princeton, New Jersey, USA.

Tonn, W. M., C. A. Paszkowski, and I. J. Holopainen. 1992. Piscivory and recruitment: mechanisms structuring prey populations in small lakes. Ecology 73:951-958.

Turner, A. M. 1996. Freshwater snails alter habitat use in response to predation. Animal Behavior 51:747-756.

Turner, A. M. 1997. Contrasting short-term and long-term effects of predation risk on consumer habitat use and resources. Behavioral Ecology 8:120-125. 
Turner, A. M., R. J. Bernot, and C. M. Boes. 2000. Chemical cues modify species interactions: the ecological consequences of predator avoidance by freshwater snails. Oikos 88: $148-158$.

Turner, A. M., and G. G. Mittelbach. 1990. Predator avoidance and community structure: interactions among piscivores, planktivores, and plankton. Ecology 71:2241-2254.

Van Buskirk, J., and K. L. Yurewicz. 1998. Effects of predators on prey growth rate: relative contributions of thinning and reduced activity. Oikos 82:20-28.

Vandermeer, J. H. 1969. The competitive structure of communities: an experimental approach with Protozoa. Ecology 50:363-372.

Wahl, M., M. E. Hay, and P. Enderlein. 1997. Effects of epibiosis on consumer-prey interactions. Hydrobiologia 355:49-59.

Wainwright, P. C., C. W. Osenberg, and G. G. Mittelbach. 1991. Trophic polymorphism in the pumpkinseed sunfish (Lepomis gibbosus linnaeus): effects of environment on ontogeny. Functional Ecology 5:40-55.

Wedekind, C., and M. Milinski. 1996. Do three-spined sticklebacks avoid consuming copepods, the first intermediate host of Schistocephalus solidus: An experimental analysis of behavioural resistance. Parasitology 112:371-383.

Wellborn, G. A., and J. V. Robinson. 1991. The influence of fish predation on an experienced prey community. Canadian Journal of Zoology 69:2515-2522.

Wellborn, G. A., D. K. Skelly, and E. E. Werner. 1996. Mechanisms creating community structure across a freshwater habitat gradient. Annual Review of Ecology and Systematics 27:337-363.

Werner, E. E. 1991. Nonlethal effects of a predator on competitive interactions between two anuran larvae. Ecology 72:1709-1720.

Werner, E. E. 1992. Individual behavior and higher-order species interactions. American Naturalist 140:S5-S32.

Werner, E. E. 1998. Ecological experiments and a research program in community ecology. Pages 3-26 in W. J. Resetarits and J. Bernardo, editors. Experimental ecology: issues and perspectives. Oxford University Press, Oxford, UK.

Werner, E. E., and B. R. Anholt. 1993. Ecological consequences of the tradeoff between growth and mortality rates mediated by foraging activity. American Naturalist 142: 242-272.

Werner, E. E., and B. R. Anholt. 1996. Predator-induced behavioral indirect effects: consequences to competitive interactions in anuran larvae. Ecology 77:157-169.
Werner, E. E., and J. F. Gilliam. 1984. The ontogenetic niche and species interactions in size-structured populations. Annual Review of Ecology and Systematics 15:393-425.

Werner, E. E., J. F. Gilliam, D. J. Hall, and G. G. Mittelbach. 1983. An experimental test of the effects of predation risk on habitat use in fish. Ecology 64:1540-1548.

Werner, E. E., and D. J. Hall. 1988. Ontogenetic habitat shifts in the bluegill sunfish (Lepomis macrochirus): the foraging rate-predation risk trade-off. Ecology 69:1352-1366.

Werner, E. E., and M. A. McPeek. 1994. Direct and indirect effects of predators on two anuran species along an environmental gradient. Ecology 75:1368-1382.

Wilbur, H. M. 1972. Competition, predation, and the structure of the Ambystoma-Rana sylvatica community. Ecology 53: $3-21$.

Wilbur, H. M., and J. E. Fauth. 1990. Experimental aquatic food webs: interactions between two predators and two prey. American Naturalist 135:176-204.

Willis, E. O. 1969. On the behavior of five species of Rhegmatorhina, ant-following antbirds of the Amazon basin. Wilson Bulletin 81:363-395.

Wimberger, P. 1991. Causes of morphological plasticity in cichlid fishes. Dissertation. Cornell University, Ithaca, New York, USA.

Wissinger, S., and J. McGrady. 1993. Intraguild predation and competition between larval dragonflies: direct and indirect effects of shared prey. Ecology 74:207-218.

Wissinger, S., H. H. Whiteman, G. B. Sparks, G. L. Rouse, and W. S. Brown. 1999. Foraging trade-offs along a predator-permanence gradient in subalpine wetlands. Ecology 80:2102-2116.

Wootton, J. T. 1992. Indirect effects, prey susceptibility, and habitat selection: impacts of birds on limpets and algae. Ecology 73:981-991.

Wootton, J. T. 1993. Indirect effects and habitat use in an intertidal community: interaction chains and interaction modifications. American Naturalist 141:71-89.

Wootton, J. T. 1994. Putting the pieces together: testing the independence of interactions among organisms. Ecology 75:1544-1551.

Worthen, W. B., and J. L. Moore. 1991. Higher-order interactions and indirect effects: a resolution using laboratory Drosophila communities. American Naturalist 138:10921104.

Yodzis, P. 1988. The indeterminacy of ecological interactions as perceived through perturbation experiments. Ecology 69:508-515. 